\title{
Examining factors that shape Technical Vocational Education and Training engineering students' understanding of their career choices
}

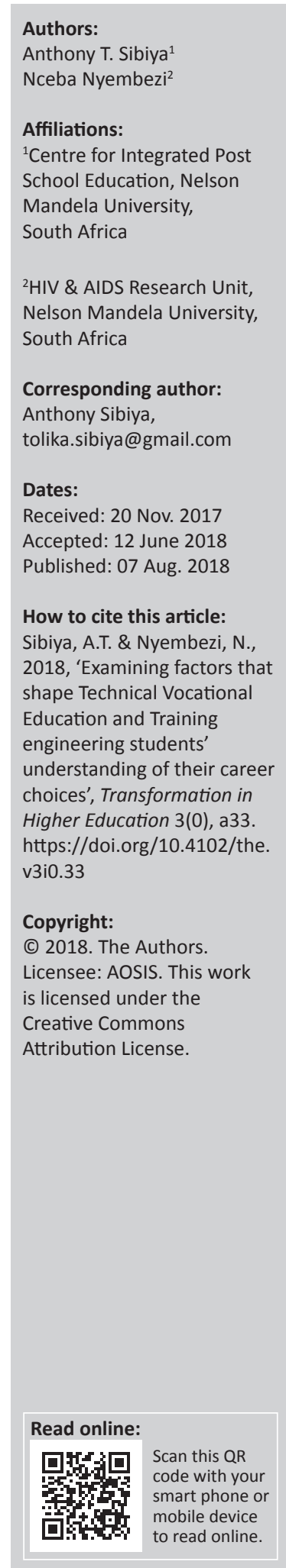

Background: This article seeks to examine factors that shape Technical Vocational Education and Training (TVET) engineering students' understanding of their future career choices. Moreover, given the promising and ambitious vision for growth in both TVET and Higher Education Institutions (HEIs), as envisaged by the policy framework, White Paper on Post School Education and Training (PSET) aimed at addressing the challenges, amongst others, of youth unemployment.

Objectives: The objective of this article is to ascertain factors that inform students' understanding of their future career prospects.

Methods: In this research, qualitative self-administered, open-ended questionnaires were employed as a data collection tool to gather facts about students' beliefs, feelings and experiences regarding certain engineering programmes and services offered at TVET colleges. Consequently, purposive sampling was utilised to sample 113 engineering participants who voluntarily completed the questionnaires, which were organised to gather the required data.

Results: The findings of the study point to divergent views, where some students felt very strongly that TVET engineering qualification leads to full employment because of the demand for this skill, while other students argued that the high rate of unemployment in South Africa is so deep such that even graduates irrespective of qualification are not guaranteed employment in South Africa.

Conclusion: Consequently, the researchers believe that the TVET's learning programmes should be repositioned to articulate as a poor response to poor schooling in relation to labour market, amongst others, to ease school leavers into jobs or self-employment under conditions of widespread youth unemployment.

\section{Introduction}

South Africa currently is grappling with serious socio-economic challenges of poverty, inequality and high rates of unemployment. This is in the context of the recently reported 2.8 million of the 6.8 million 18-24-year olds in South Africa who are classified as 'not in education, employment or training' (hereafter NEET) (Department of Higher Education and Training 2012). Young people in general, particularly graduates, are therefore increasingly without work in South Africa, and the researcher argues that it appears to be no guarantee of employment after gaining a qualification, even for those with qualifications within the scarce skills categories of Science, Technology, Engineering and Mathematics (STEM). Consequently, the research was conducted to examine the Technical and Vocational Education and Training (TVET) engineering students' understanding of their future career prospects. It concerned the researcher that the problem of unemployment amongst the youth was growing unabated and besides being a subject of many vigorous debates in South Africa. Again, the Statistics of South Africa (2016) affirmed the issue of unemployment when released a quarterly report stating that unemployment in the country was $26.7 \%$, and the report came after the lager National Skills Development Strategy III was identified and emphasised as a key educational and skills development response in solving unemployment crisis facing the youth for instance. In the discourse on skills and unemployment, young people are being blamed for their unemployment; an article by Sharp (2012) is a case in point, where he argues that the central description in this regard is that young people are simply making poor career choices and therefore are responsible for their inability to access gainful employment. Again, Bhorat (2012) concurs and further argues that young people find it hard to access the world of work to secure work-based skills and experience, and government policy intervention such as youth wage subsidy is not much of assistance. 


\section{Problem statement}

The problem of youth and graduate unemployment has been identified in various research reports including the National Treasury report (2011), which suggest that there were about 3 million unemployed youth in South Africa. This report corresponds with the DHET report on youth unemployment cited above and adds that more than 600000 graduates with post-matric qualifications were unemployed (Bhorat 2012). As the researcher argued above, the frequent narrative is that young people, because of their poor career choices, are partly responsible for their unemployment status, and because of their laziness in some instances, some educational pundits blame the inadequate career exhibitions as the reason why young people often choose careers that lack industry relevance (Bhorat 2012). In this instance, Baatjes, Baduza and Sibiya (2014) argue that the problem of youth unemployment is framed within competing discourses of a skills crisis versus a job crisis. They argue that many scholars have perceived the skills mismatch and lack of graduate preparedness as the dominant discourse, which also links poor choices made by students to unemployment. Yet, at the same time, young people and students, in particular, are falling into the gaps, facing long-term (if not permanent) unemployment. Consequently, as Baatjes et al. explains, TVET sector faces the largest deficit and requires the greatest intervention. The Department of Higher Education through the White Paper for Post School Education and Training (PSET 2014) aims to expand the TVET sector in terms of enrolment and further ensures that SETA plays a facilitating role to ensure greater partnership and collaboration between TVETs and industries. This is a response to the growing needs of vocational skills; thus, unemployment facing the country explains the department.

However, Baatjes et al. (2014) argue that the escalating interest in vocational education has mainly been driven, amongst others, by the marginal status of vocational training, and in the last decade, the importance of vocational education has come into sharper focus because of radical changes in the global economic system. As such, changes have been combined with rapid scientific and technological innovation and transfer, which are premised on the demand for new ways of preparing young people for the labour market (Baatjes et al. 2014). They further contend that the role of vocational education has been regarded as a primary source in increasing the supply side of human capital for the economy, as well as addressing the increasing unemployment amongst the youth.

Having explained the problem, the question that lingers in the researchers is: To what extent, if any, do TVET college engineering students believe they will be employable after completing their engineering qualifications, considering high rates of unemployment in South Africa?

Research sub-question: What are the factors that shape students' career choices and how could these factors be examined or be interpreted to fully respond to the unemployment question? What informs students understanding of their future career prospects?

\section{Theoretical framework}

The study adopted human capital theory as a theoretical lens through which the study is embedded. The human capital theory has influenced and shaped education and training systems across the globe. Consequently, the vocational education and training programmes in the South African context encourage or are rather inspired by human capital approach to human progress and development. Through this theory, investment in the education of individuals is regarded as the solution to all the structural problems of the economy and the labour market (Baptiste 2001).

Furthermore, the proponents of human capital theory argue that this concept of human capital originally refers to knowledge, attitudes and skills primarily developed and valued for productivity in the economy (Baptiste 2001). $\mathrm{He}$ further explains this notion that education is the most important single determinant of economic growth, which was initially advanced through the work of the human capital theorists Gary Becker and Theodor Schultz in the 1960s and 1970s (Baptiste, 2001). Again, according to him, Becker and Schultz believed that well-educated persons are more productive and are likely to get well-paying jobs (Baptiste 2001). In this instance, the researcher's employ of human capital theory has been selected as the theoretical framework, because the current vocational education and training and its application in South Africa advances the failed approach to human development.

The defining feature of economic debates in recent decades is the importance to which neo-classical economics have attached human capital as a determining factor of economic success and competitive advantage (Brown, Green \& Lauder 2000). They further explain that it is a naïve argument that education is the most important and only single determinant of economic growth, which was initially advanced through the work of the human capital theorists Gary Becker and Theodor Schultz in the 1960s and early 1970s (Brown et al. 2000). Again, for them these theorists have reduced human behaviour to calculation rationality, wherein human beings are seen as purposeful and goal-oriented individuals who will, with no option, invest in the education in order to maximise their employment status (Brown et al. 2000). As consequence, Brown (1999) argues that human capital theory, which brought about new economies that needed highly skilled and qualified personnel, has thus proven to be a failure in relation to human development. Accordingly, Motala and Treat (2014) also support this critique, as they argue very strongly that the assumption that markets satisfy the pre-existing desires of consumers completely ignores the obvious ways in which markets manufacture needs and desires as opposed to merely responding to them. For Motala and Treat, this proposition has since been severely criticised in a growing body of research, and the limitations of human capital theory have become even more obvious because of the global economic crises. The growing critique of this narrowly conceived notion of education in relation to social human development has been exposed for what it is, 
not only with an advanced and well-grounded argument against it and its failures, but decry human beings being regarded on the same plane as machines or technological advancements.

Human capital theorists construe social inequalities not as injustice or the results of exploitation and oppression, but rather as the natural and inevitable outcomes of a competitive, free market (Baptiste 2001). To them, free markets are the most legitimate social institutions; that is, they are the only institutions that can adequately and justly govern, regulate and explain human behaviours and achievements and the definition of human capital as knowledge, attitude and skills that are developed and valued primarily for economically productive potential (Baptiste 2001). For human capital theory, investment in education accounts for economic growth; the rationale here is for education regarded as investment in human beings no different from investment in land or machines as they all represent enhancement of an economy (Ashton, Brown \& Lauder 2012). Thus, this human capital theory model advances the following:

- Education should be regarded as a private good that is a tradable commodity in the market place for money and status.

- Private return on human capital investment (education) provides an incentive to progress to further education.

- Further education should be oriented towards the labour market (supply and demand).

- More education can be translated into higher productivity, which results in higher earnings.

In this instance, Motala and Vally (2014) point out that despite a body of knowledge critiquing human capital theory, it remains central to skills formation policies in most countries. In this regard, the researcher argues for a need for alternatives instead of a continuous and uncritical adoption of human capital theory prescripts in our education for development. There has to be this new alternative to education given the wide-ranging critique of human capital theory including its one-dimensional view of human beings; narrow understanding of skills and labour; its exacerbation of social inequalities; the development of 'underdevelopment'; blaming of the victims; and the privatisation of social problems (Baptiste 2001).

\section{Methodological design}

The methodological approach used in conducting the study was a qualitative method. The researcher used a qualitative approach as a relevant method in this study as participants were given the opportunity to explain their thinking and perceptions around vocational education in relation to the labour market. This approach was carefully chosen as it aims for the depth of understanding rather than the quantity of understanding (Henning 2004). Again, explaining qualitative methodology, Ferguson (1993) describes qualitative research as a set of methods for conducting research and as a set of beliefs about our knowledge of the world. The researcher used a TVET college as a case study, situated in the interpretivist paradigm, to seek an understanding and to explore factors that shape students' understanding of their future career prospects, while Yin (2009) defines a case study as an empirical research inquiry that explores the existing phenomenon within its real-life context, especially when boundaries between phenomenon and context are not clearly articulated. As stated in the abstract, a sample of 113 students participated in the study by completing self-administered, open-ended questionnaires. The selection of participants was based on non-probability sampling, in order to easily analyse the data the researcher made use of open coding.

When describing the method of data analysis, Henning (2004) describes it as a process, wherein data are thoroughly divided into categories to ascertain similarities or contrasts. It is these categories as they are divided that are called themes (Neuman 2006). This process of dividing data or clustering them according to similarities and differences was useful and helped with the interpretation of data. Furthermore, the clustered themes also gave a detailed description of the matter under investigation and the thinking of the students thereof.

\section{Discussion on research findings}

The previous section explains in detail the methodology and design of the study. This part will discuss research findings. Suffice to say, the main findings of the research have been clustered in themes, which are further supported by few direct quotations from the student responses.

\section{Educational aspirations}

For instance, some responses from students were as follows:

'I wanted to further my studies and obtain a degree/diploma so that I can more qualified'. (Participant 11, male, 24 years old)

'My hopes and dreams were to further my studies at the university, and do electrical engineering, to fulfil my dreams because my goals were to see myself successful, become an engineer'. (Participant 18, female, 21 years old)

'I wanted to study further to pursue my dreams; to learn more and be a graduate one day, to have a bright future and fulfil my dreams to become an engineer'. (Participant 26, female, 24 years old)

These are but few examples to illustrate the educational aspiration theme. The findings suggest that participants' educational aspirations while at school were to study further after finishing high school and then obtain employment. This educational desire for employment is entrenched from human capital theory, which argues that investment in the education of individuals is the solution to all the structural problems of the economy and the labour market (Baatjes 2005). The findings however, affirm this narrow argument advanced by proponents of human capital theory that knowledge, attitude and skills, are valued for economic productive potential, meaning without these (knowledge, skills and attitude), chance of being economic productive are very low (Baptiste, 2001). This approach to education and human development is narrow as it fails to define skills 
formation as the development of the social capacity for learning, innovation and productivity (Brown 1999).

On the contrary, Marsh (2011) argues that education bears too much of the burden of our hopes for economic justice and that we ask education to accomplish things it cannot accomplish. He further argues that the appeal for education has displaced the debate about social class and economic power that progressive forces need to have if we are to understand the causes of and the cure for sustained poverty and increasing inequality. To start a debate, he argues that one needs to dismiss the belief that all or even most of our economic problems can be solved in a classroom (Marsh 2011) as this debate is being propagated by human capital theorists, who narrowly argue that education is about individual investment for personal development and success. The findings further speak to factors that shape their career choices, which amongst others is poverty and a high level of unemployment, which, combined, leads to personal ambitions cantered on personal skills.

\section{Personal skills required}

Examples of the response are as follows:

'Hard work is required and a positive attitude so that the person will not only work in the company but help it grow'. (Participant 45, male, 24 years old)

One student said:

'Companies require someone who is determined to work and employees who are always on time at work'. (Participant 48, Female, 26 years old)

In addition, another student felt strongly that firms require 'people who are good in time management and teamwork'. (Participant 54, female, 23 years old)

Students strongly believe that personal skills such as positive attitude, interpersonal skills, teamwork and time management, are necessary, and in some instances, personal skills such as positive attitude, interpersonal skills, hard work and dedication. However, they further argue that no one with required qualification should be denied access to employment, based on a lack of soft skills. In this regard, Lauglo and Lillis (1988) argue very strongly that vocational training should be about easing school leavers (NEETs) into practical jobs or training for selfsustenance or employment, especially under the conditions of widespread and worldwide unemployment of young people (Lauglo \& Lillis 1988). However, the study findings entrench the view held by Rasool and Botha (2011) that there is a widely accepted definition of skills shortage or at least how government should respond to it. The nature, scale and severity of skills shortages are therefore often miscalculated, misunderstood and misused which results in poor public policies, with their associated high levels of wastage. As a result, the reliability and validity of the labour market data is of concern (Rasool \& Botha 2011). The responses of students seem to suggest that qualification and skill are the same thing and that these should be adequate for an individual to be absorbed into the job market. Soft skills such as being hardworking, confidence, teamwork, honesty, determination and commitment cannot be a barrier to employment, as they are not taught in educational institutions. Therefore, although such soft skills are important, they should be a secondary consideration in employment with the primary factors being qualification (which at times is used interchangeably with 'skill'). The findings seem to concur with Lauglo and Lillis (1998) when they explain that the term 'vocationalisation' was meant curriculum change in a practical or vocational direction. They further argue that this is an old recurring policy theme in many countries around the world. These old but recurring policies are mainly a political response to poor articulation of schooling within the world of work (the labour market). It therefore makes sense that, as Kraak and Hall (1999) state, the TVET sector in South Africa does indeed face a multitude of complex problems. TVET systems across the globe are fundamentally shaped by the effectiveness of their articulation with the world of work as well as by the extent to which they grant meaningful access to further and higher learning. They further argue that in South Africa, this has not been the case, and as a result, the TVET system in South Africa has failed both to articulate itself to the world of work and to further higher learning (Kraak \& Hall 1999). For them, this failure within the system in relation to the quality and relevance of TVET programmes leads to inadequate preparation for higher learning and articulation of the path to the world of work (Kraak \& Hall 1999). Again, in this instance, Baatjes et al. (2014) concur and further explain that in its current form the TVET sector has failed to link young learners to real employment prospects. It has also failed to provide a meaningful learning pathway for employed adult workers to return to formal study to improve their overall skills and competencies. Increasing joblessness and underemployment amongst graduates is now being explained as a failure of curriculum models, including the lack of proper work-based learning or workintegrated tools as these fail to provide the essential skills required by the labour market (Baatjes et al. 2014). One can therefore conclude, based on these findings and discussion, that there is no linear relationship between vocational education and training and the labour market. Suffice to say, having an education does not automatically lead to employment, as it is not that simple.

\section{Employment opportunities in South Africa}

Again, here are some of the responses taken directly from the questionnaires regarding job opportunities in South Africa. These findings are a direct response to the question: In your opinion, what is the primary reason for youth unemployment in South Africa? One student responded that 'there is job scarcity and many people in South Africa and some are uneducated due to money problems which prevent 
them from studying further'. And others responded that 'Graduates are the ones who are unemployed here in South Africa; those who are successful don't have qualifications whilst graduates are unemployed'. In addition, one student responded that ' the value of the rand isn't powerful so work opportunities are scarce'. In this regard, students blame the state for its inability to create conducive environment for job creation. Young people are also required to have experience they do not have, so experience is also a barrier to any job opportunities that may be available in the market. One student asked in response to a questionnaire: How do you expect graduates to have experience when they leave colleges or universities. They argued though that for them the primary reason for unemployment is that jobs are scarce regardless of one's educational status. Furthermore, students argue that college education is not recognised in the labour market, as it seems there is no value in vocational training in South Africa.

Unemployment remains one of the major societal and macro-economic problems facing South Africa today and as such needs a holistic approach to youth development (Baatjes et al. 2014). As a result of this problem of jobs, one major policy should ensure that the youth do not lose touch with the labour market (Baatjes et al. 2014). Again, the student's response legitimised the National Treasury report (2011) which stated that over $30 \%$ of $18-24$-year olds with tertiary education, which include university degrees, university of technology diplomas and college certificates were unemployed. Educational pundits such as Allais and Nathan (2014) argue that the South African economy has experienced what has been commonly referred to as jobless growth with capital, rather than labour-intensive forms of economic growth being the order of the day (Allais \& Nathan 2014). However, employers do not seem to agree with a view that unemployment is because of job scarcity; instead, they argue to the contrary and say there is a mismatch of skills. For instance, Belt, Campbell and Gilles (2010) argue that a mismatch of skills in the labour market happens when employers are unable to, or have difficulty in employing people they need because they are not readily available in sufficient numbers with the required skills (Belt et al. 2010). Students are vehemently opposed to this dominant narrative of a mismatch of skills as purported by many including business in the discourse of skills and employment. Contrary to the popular narrative of skills shortage or mismatch as the reason for unemployment in the public domain, students seem to argue that lack of experience is the reason why young people are unemployed. This argument is further supported by Prinsloo (2011) who contends that graduates in the fields of engineering and science, mainly from South Africa's Further Education and Training colleges (now TVET), are given the knowledge and some practical training by institutions, but then left without any work experience, and ultimately, unemployment. The lack of employment or job opportunities for young people, particularly graduates from student's perspective, appears to be in opposition to the dominant view, which is lack of skills or skills mismatch.
Student's perspective affirms Brown's (1999) argument that the challenge of unemployment and poverty as a global phenomenon is understood differently within different national contexts. Furthermore, Brown (1999) argues that seeing the economy as analytically distinct from its social, cultural and political dimensions is neo-classical in approach and impedes the understanding of skills requirements. This neo-classical approach in seeing the economy as distinct from its social and cultural dimensions is critical for the mainstream economic analysis because it ignores the fact that individual actions are embedded in a social context and that norms, interpersonal trust, social networks and social organisation are functions not only of society but also of the economy.

\section{Recommendations}

There should be more research conducted to explore the relevance of the curriculum content of TVET programmes in relation to needs of society and economy. The researcher in this regard suggests that there ought to be a study that explores the experiences of NEETs group on vocational education programmes. The college sector has to sharpen, equip and strengthen its research capacity; and remove outdated materials and machines, which are no longer relevant in modern day technology advancement.

The democratic state has a responsibility to ensure that vocational education protects democratic ideals while still preparing students for future career challenges, beyond meeting narrow business-only needs. A morally appropriate model for vocational education is found within a comprehensive democratic approach rather than what is currently available at the present moment and which are narrowly conceived as skills-based programmes.

It is the researcher's further suggestion that vocational education and training should be improved to better serve and equip individuals with knowledge and skills necessary to survive in their daily lives and further be context based. In addition, the researcher argues that vocational skills programmes must speak to people's rural context and should support their way of life. The White Paper on Post School Education and Training should directly guide the Education Department and other institutions towards building a developmental state with a vibrant democracy and flourishing economy. Furthermore, both HEIs and TVETs should collaboratively develop a responsive and context based curriculum that addresses the needs of the society. This should be the case because the researcher argues that a market-inspired curriculum, which targeted a particular segment to respond to market needs, have proven to be disastrous, as it produced social inequalities and exclusion. Again, a market-led curriculum, instead of responding to social issues, it manufactures them. Lastly, the Department of Higher Education should rather facilitate a discussion that begins to re-orientate vocational education in South Africa and furnish young people with the knowledge and skills they need in life as well as to contribute to societal development. 


\section{Conclusion}

The study examined factors that shape TVET engineering students' understanding of their career choices. It further sampled 113 participants who were doing their final year of engineering-related qualifications, and data analysis was performed through thematic categorisation. The analysis and discussion revealed divergent views shared by the participants, regarding unemployment especially of TVET graduates. Some strongly felt that a TVET qualification, especially engineering, leads to full employment because of its demand and that TVET normally assists students through placement unit, making it easier to get a job. While other argued that whatever qualifications one hold, the world of work is not ready for them, because of a lack of experience. They described this as an unfair expectation from graduates, as they cannot get it without being properly monitored and trained by the very same industry that hopes to absorb them in the near future. For them, the real reasons for the high level of unemployment are because of scarcity of jobs and because the economy fails to produce enough jobs, not skills shortage as often articulated in the media. Unemployment in South Africa is very high amongst the youth, and the most distressing aspect is the extent to which it has grown in the democratic era. Its rise affects not only the NEET group but also those who have interfaced with education institutions such as universities and TVET colleges; graduates are affected by this social condition simply because there are no jobs readily available.

\section{Acknowledgements}

The Centre for Integrated Post Schooling Education and Training, (Nelson Mandela University), carried out the costs of professional editors, who were responsible to check spelling, grammatical errors in the article.

\section{Competing interests}

The authors declare that they have no financial or personal relationships, which may have inappropriately influenced them in writing this article.

\section{Authors' contributions}

A.T.S., the first author was responsible for the overall research in terms of data collection, data presentation and analysis while N.N. during this phase of the research was responsible for overall supervision and guidance. A.T.S. wrote the article extensively and N.N. was responsible for an overall conceptualisation of the article and technical issues related checking whether there is inclusion of theoretical framework, and whether methodology is well explained and justified.

\section{References}

Allais, S. \& Nathan, O., 2014, 'What jobs? Skills? What skills? An overview of studies examining relationships between education and training and labour', in S. Vally \& E. Motala (eds.), Education, economy, and society, pp. 103-124, Unisa Press, Pretoria.

Ashton, D., Brown, P. \& Lauder, A., 2012, The global auction: The broken promises of education, jobs, and incomes, Oxford University Press, Oxford.

Baatjes, I., 2005, 'Neoliberal fatalism and the corporatisation of higher education in South Africa, education as market fantasy or education as a public good', in S.A. Vally (ed.), Quarterly Review of Education and Training 12(1), 25-33.

Baatjes, I., Baduza, U. \& Sibiya, A.T., 2014, 'Building a transformative pedagogy in vocational education in South Africa, pp. 81-102, in S.A. Vally (ed.), Education, society and economy, UNISA Press, Pretoria.

Baptiste, I., 2001, 'Educating lone wolves: Pedagogical implications of human capital theory', Adult Education Quarterly 3(55), 184-201. https://doi.org/10.1177/ 074171360105100302

Belt, V., Campbell, M. \& Giles, L., 2010, Skills for jobs: Today and tomorrow the National strategic skills Audi for England, The evidence report, vol. 2, UK Commission for Employment and Skills, UK.

Bhorat, H., 2012, Young, jobless and desperate- Degree with no guarantees, viewed 21 October 2013, from http://www.citypress.co.za/news/young-jobless-and-desperatedegrees-with-no-guarantees-20120616/

Brown, P., 1999, 'Globalization and the political economy of high skills', Journal of Education and Work 13(12), 233-251.

Brown, P., Green, \& Lauder, H., 2000, High skills: Globalization, competitiveness and skill formation, Oxford University Press, New York.

Department of Higher Education and Training, 2012, Green paper of post-School education and training, DHET, Pretoria.

Department of Higher Education and Training, 2014, Building an expanded, effective and integrated post-school System: A White Paper on Post School Education and Training, DHET. Pretoria.

Ferguson, D., 1993, 'Something a little out of the ordinary: Reflections on becoming an interpretivist researcher in special education', SAGE Journal of Remedial and Special Education 4(14), 35-43. https://doi.org/10.1177/074193259301400408

Henning, E., 2004, Finding your way in qualitative research, Van Schaik, Pretoria.

Kraak, A. \& Hall, G., 1999, Transforming further education and training in South Africa: Volume one - qualitative findings and analysis, HSRC, Pretoria.

Lauglo, J. \& Lillis, K., 1988, Vocationalizing education - An international perspective, Pergamon Press, London.

Marsh, J., 2011, Class dismissed: Why we cannot teach or learn our way out of inequality, Monthly Review Press, New York.

Motala, E. \& Treat, J., 2014, Education and jobs don't add up: Market driven skills policies limit potential of social development, viewed 17 July 2014, from http:// mg.co.za/article/2013-01-29-education-and-jobs-dont-add-up

National Treasury, 2011, Confronting youth unemployment: Policy options for South Africa, National Treasury, Pretoria.

Neuman, W., 2006, Social research methods - Qualitative and quantitative approaches, Pearson Education Inc, Whitewater.

Prinsloo, L., 2011, Lack of work experience leaves graduates unemployed, viewed 23 July 2016, from http://www.engineeringnews.co.za/article/lack-of-work-experienceleave-graduates-unemployed-2011-05-20

Rasool, F. \& Botha, C.J., 2011, 'The nature, extent and effect of skills shortages on skills migration in South Africa', SA Journal of Human Resource Management 1(9), 287. https://doi.org/10.4102/sajhrm.v9i1.287

Stats-SA, 2016, Statistics South Africa: Quarterly Labour Force Survey 2, viewed 18 August 2016, from www.statssa.gov.za//publications//po211//po2111tsquater2016. pdf

Sharp, L., 2012, Young, jobless and esperate - Degrees with no guarantees, viewed 16 June 2016, from http:www.citypress.co.za/news/young-jobless-and-desperatedegrees-with-no-guarantees

Yin, R., 2009, 'Case study research design and methods', Canadian Journal of Action Research 14(1), 69-71. 